\title{
Reliability of Cephalogram in Determining Skull Gender Dimorphism
}

\author{
Sidra Butt, ${ }^{1, *}$ and Imtiaz Ahmed ${ }^{1}$ \\ ${ }^{1}$ Department of Orthodontics, Dr. Ishrat ul Ebad Khan Institute of Oral Health Sciences, DUHS Karachi, Pakistan \\ "Corresponding author: Sidra Butt, Department of Orthodontics, Dr. Ishrat Ul Ebad Khan Institute of oral Health Sciences, DUHS Karachi, Pakistan. Tel: +92-3333349116, E-mail: \\ den.sid7@gmail.com
}

Received 2016 January 08; Accepted 2016 January 30.

\begin{abstract}
Background: The forensic anthropologists have been vastly studied the dimorphism in teeth, hair, pelvis, skull and in bone sizes. Objectives: To investigate the gender dimorphic potential of cephalometric parameters.

Materials and Methods: Thirteen angular and twenty-one linear lateral cephalometric measurements were analyzed on randomly selected manual tracings of sixty-nine male and sixty-nine female cephalograms between the ages twenty to fifty years.

Results: $\mathbf{9 1 . 3 \%}$ males correctly classified in the data, on the basis of discriminant function we made, similarly, 97.1\% females were correctly classified in their specific group by the help of this discriminant function. The percentage of skulls correctly classified with this function was $94.2 \%$.

Conclusions: $94.2 \%$ of original grouped cases correctly classified. For higher results extensive research with large sample size and both linear and angular cranial dimorphic traits for gender identification is proposed.
\end{abstract}

Keywords: Skull Dimorphism, Dental Radiology and Imaging, Lateral Cephalogram, Discriminant Function, Forensic Dentistry

\section{Background}

Is the patient a male or a female? This is usually the first naturally occurring thought that comes into the clinician's mind before going into the case detail. Determining sex is vital for an individuals' identification from birth till death as it is a foundational component of the biological profile. Not only the diseases but even the growth, development and aging have gender specific features. The forensic anthropologists have been vastly studied the dimorphism in teeth, hair, pelvis, skull and in bone sizes. It is only possible once the male or female has reached adolescence or adulthood.

Second best region to determine dimorphism between the sexes is the human skull. Skull bones that are available as the human remains can be used for identification of sex for civil or criminal intend when there is limitation for the application of finger printing method of human identification. Dimorphic traits of human skull are used widely reporting 77 to $92 \%$ accuracy of anthropometric measurements. Whereas, the studies conducted for the sex discrimination using cephalograms have claimed 80 to $100 \%$ accuracy (1-3). It also has been calculated that a group of traits are required for precise diagnosis instead of deliberating single character. Sex-related skeletal features are not obvious in children's bones. Elusive differences are detectable but they become more defined following puberty and sexual maturation.
Zeh et al. (2) stated determination of sex with 95\% reliability when using pelvis alone, 92\% using the skull alone and $98 \%$ using both the pelvis and the skull.

Other than its orthodontic use, the readily available equipment for cephalogram can make it a practicable tool of the forensic investigation as well specifically in medicolegal cases of unidentified severed heads in events of burn, murder, accidents, suicide bombing and war.

Hence, by using lateral cephalograms, this descriptive study is undertaken to evaluate potential sex differences in linear and angular lateral cephalometric readings. Discriminant function analysis is applied statistical technique for sex discrimination. The aim of the analysis is to determine whether these variables will discriminate between the gender or not.

\section{Objectives}

To investigate the gender dimorphic potential of cephalometric parameters.

\section{Materials and Methods}

The sample size for this study consists of 138 subjects. Study population comprised of adults, 69 males and $69 \mathrm{fe}-$ males between the ages 18 years to 50 years, visited Department of Orthodontics, Dr. Ishrat ul Ebad Khan institute of oral health sciences, Karachi, Pakistan. Good quality lateral 
cephalograms of all subjects of known sexes are randomly selected. Cephalometric points were located and marked by a single investigator. Individuals with the history of facial asymmetry, trauma, hereditary, congenital, developmental or nutritional disturbances, prolonged illness, previous orthodontics or orthognathic treatment or surgery of skull are not included.

The undermentioned linear and angular parameters (Table 1: Linear ( $\mathrm{mm}$ ) Cephalometric Variables and Table 2 Angular $\left({ }^{\circ}\right)$ Cephalometric Variable) were measured by using lateral cephalometric landmarks (Figure 1: landmarks) traced on acetate paper (Figure 2 Cephalometric parameters: Linear and Figure 3 Cephalometric parameters: Angular).

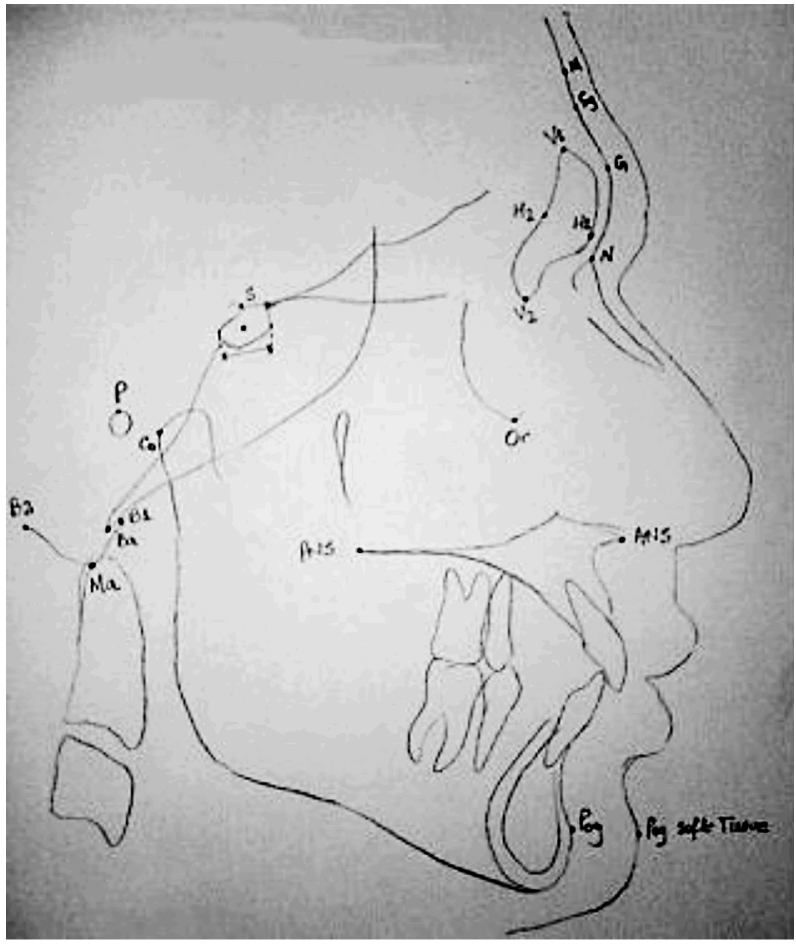

Figure 1. Landmarks

\subsection{Statistical Analysis and Results}

The data was analyzed employing statistical software SPSS version 16.0. Direct discriminant function analysis applied to calculate specific discriminant function equation for all parameters. It selects the minimum number of traits yielding maximum discriminatory effectiveness. Statistically the mean differences of all the measurements were significant. Mean female values of all linear variables were smaller than the male mean values except ULTc which
Table 1. Linear (mm) Cephalometric Variables

\begin{tabular}{|c|c|}
\hline Variables & Description \\
\hline Ba-ANS & $\begin{array}{c}\text { Most inferior posterior point in the sagittal plane } \\
\text { on the anterior rim of foramen magnum(Ba) to } \\
\text { the tip of the bony anterior nasal spine in the } \\
\text { median plane(ANS) }\end{array}$ \\
\hline Ba-N & $\begin{array}{l}\text { Most inferior posterior point in the sagittal plane } \\
\text { on the anterior rim of foramen magnum(Ba) to } \\
\text { the most anterior point of the frontonasal suture } \\
\text { in the median plane(N) }\end{array}$ \\
\hline N-ANS & $\begin{array}{l}\text { The most anterior point of the frontonasal suture } \\
\text { in the median plane( } \mathrm{N} \text { ) to the tip of the bony } \\
\text { anterior nasal spine in the median plane(ANS) }\end{array}$ \\
\hline N-Me & $\begin{array}{l}\text { The most anterior point of the frontonasal suture } \\
\text { in the median plane(N) to the most inferior } \\
\text { midpoint on the mandibular symphysis(Me) }\end{array}$ \\
\hline Fs-Wd & Frontal sinus width \\
\hline Fs-Ht & $\begin{array}{l}\text { Distance between the upper limit( V1) and lower } \\
\text { limit(V2) of frontal sinus }\end{array}$ \\
\hline Ma-SN & $\begin{array}{l}\text { Lowest point of mastoid bone(Ma) to sella-nasion } \\
\text { plane(SN) }\end{array}$ \\
\hline Ma-FH & $\begin{array}{l}\text { Lowest point of mastoid bone(Ma) to Frankfort } \\
\text { plane(FH) }\end{array}$ \\
\hline Ma-Ht & Porion to mastoidale \\
\hline Ma-wd & $\begin{array}{l}\text { Maximum width of the mastoid in the } \\
\text { anterior-posterior direction. }\end{array}$ \\
\hline ANS-Me & Lower anterior facial height \\
\hline GSgN & $\begin{array}{l}\text { Distance between glabella and the supraglabellare } \\
\text { to nasion line }\end{array}$ \\
\hline SgGM & $\begin{array}{l}\text { Distance between supraglabellare and the glabella } \\
\text { to metopion line }\end{array}$ \\
\hline$S^{\prime}-\mathbf{C o}$ & $\begin{array}{c}\text { Projection of sella on FH plane-projection of } \\
\text { Condylion on } \mathrm{FH}\end{array}$ \\
\hline Sella length & $\begin{array}{l}\text { The distance from tuberculum sella to posterior } \\
\text { clinoid }\end{array}$ \\
\hline Sella width & The largest antero-posterior dimension \\
\hline Sella height anterior & $\begin{array}{l}\text { The vertical distance, as measured perpendicular } \\
\text { to the FH plane, from tuberculum to the sella floor }\end{array}$ \\
\hline Sella height posterior & $\begin{array}{l}\text { The vertical distance, as measured perpendicular } \\
\text { to the FH plane, from posterior clinoid to the sella } \\
\text { floor }\end{array}$ \\
\hline ULTC & Ratio of total chin thickness to upper lip thickness \\
\hline GPI & Glabella projection index $=\mathrm{GSgN} \times 100 / \mathrm{SgN}$ \\
\hline G-SI-PI & $\begin{array}{l}\text { Glabella superior-inferior projection index-a } \\
\text { measure of the location of glabella along the } \\
\text { midsagittal plane }=\mathrm{GSg} / \mathrm{GN} \text {. }\end{array}$ \\
\hline
\end{tabular}

is larger in females by $0.3 \mathrm{~mm}$ while all the angular measurements are smaller in males except GMSN, GMFH, GMBaN, GNGSg and GSGM with the P value 0.000. The result of all the variables are presented in Table 3 (Group Statistics according to sex and in total).Group means and standard deviations with large separations indicating these 
Table 2. Angular $\left(^{\circ}\right)$ Cephalometric Variable

\begin{tabular}{|c|c|}
\hline Variable & Description \\
\hline GSgM & $\begin{array}{l}\text { Angle between the metopion to supraglabellare line and the } \\
\text { supraglabellare to glabella line }\end{array}$ \\
\hline GMBaN & $\begin{array}{l}\text { Angle between the glabella to metopion line and the basion to } \\
\text { nasion line }\end{array}$ \\
\hline GMSN & $\begin{array}{l}\text { Angle between the glabella to metopion line and the sella to } \\
\text { nasion line }\end{array}$ \\
\hline GMFH & $\begin{array}{c}\text { Angle between the glabella to metopion line and the porion to } \\
\text { orbitale line }\end{array}$ \\
\hline Ba-N-Me & Angle between basion and nasion and menton \\
\hline Me-N-ANS & Angle between menton and nasion and anterior nasal spine \\
\hline S-N-Me & Angle between sella and nasion and menton \\
\hline SNAr & Angle between $\mathrm{SN}$ plane and articulare \\
\hline GNGSg & Angle between lines glabella-nasion and glabella-supraglabella \\
\hline GSGM & Angle between lines glabella-sella and glabella-metopion \\
\hline GS-SN & Angle between lines glabella-sella and sella-nasion \\
\hline SN-SMa & Angle between lines sella-nasion and sella-mastoidale \\
\hline GS-GN & Angle between lines glabella-sella and glabella-nasion \\
\hline
\end{tabular}

Figure 2. Cephalometric Parameters: Linear

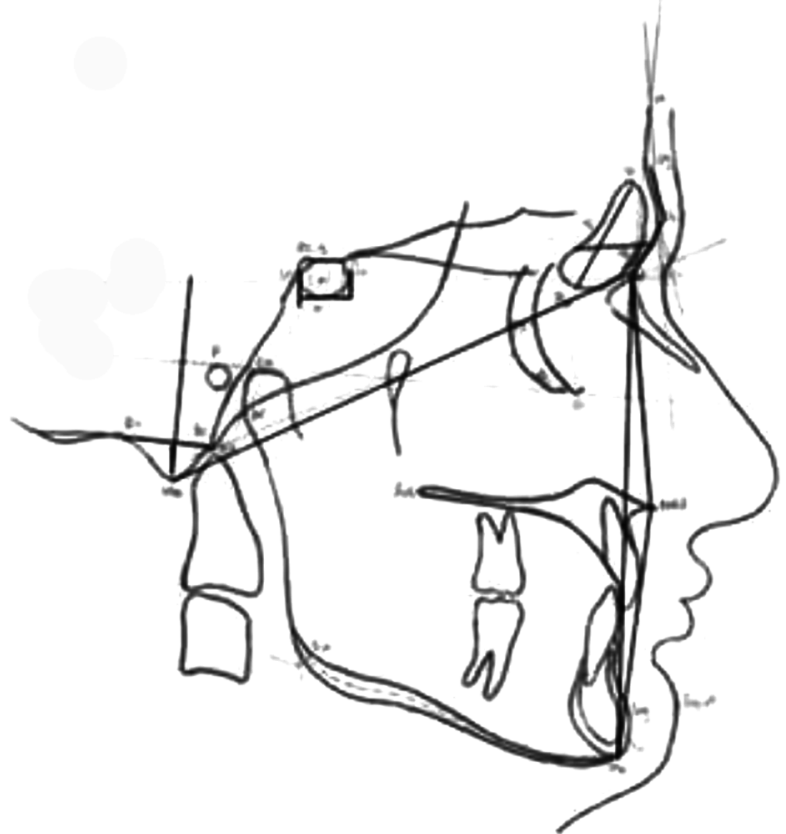

I, Ba-ANS; II, Ba - N; III, N - ANS; IV, N - Me; V, Fs - Wd; VI, Fs - Ht; VII, Ma - SN; VIII, Ma - FH; IX, Ma - Ht; X, Ma - wd; XI, ANS - Me; XII, GSgN; XIII, SgGM; XIV, S' - Co'; XV, Sella length; XVI, Sella width; XVII, Sella height anterior; XVIII, Sella height posterior; XIX, ULTc; XX, GPI; XXI, G-SI-PI.
Figure 3. Cephalometric Parameters: Angular

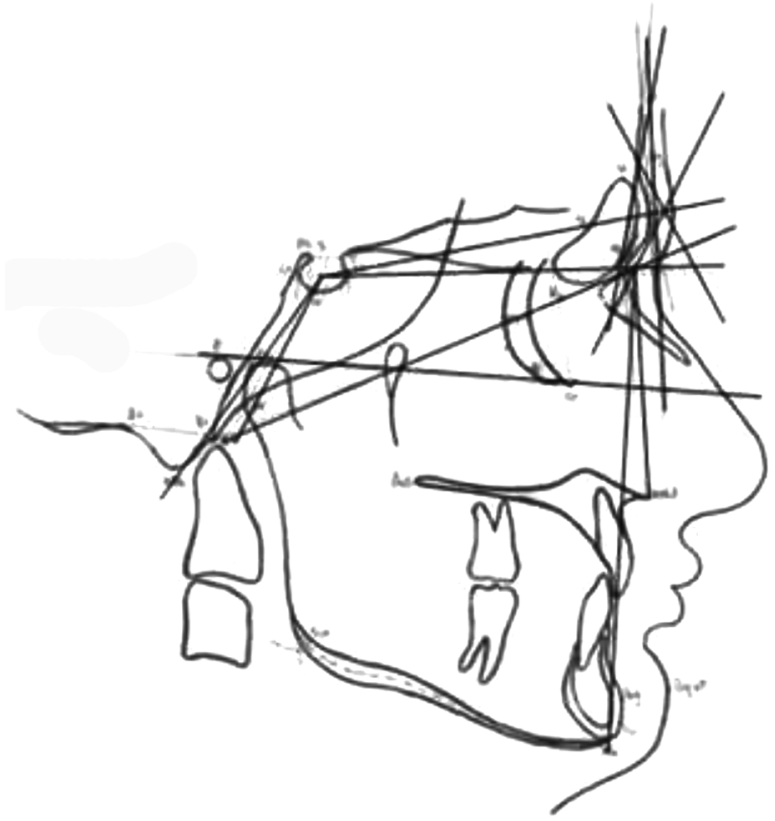

I, GSgM; II, GMBaN; III, GMSN; IV, GMFH; V, Ba-N-Me; VI, Me-N-ANS; VII, S-N-Me; VIII, SNAr; IX, GNGSg; X, GSGM; XI, GS-SN; XII, SN-SMa; XIII, GS-GN.

variables may be good discriminants. Wilks' lambda indicates the significance of the discriminant function. Table 4 (Wilk's Lambda) indicates a highly significant function $(\mathrm{P}<.000)$ and provides the proportion of total variability not explained, so we have $27.8 \%$ unexplained. The resulted canonical discriminant 0.850 showed high correlation between the discriminate function and independent variables. Table 5 Functions at Group Centroids (Unstandardized canonical discriminant functions evaluated at group means) shows male are more associated in classification as compare to females. Females have negative association in classification, Male versus female, $90 \%$ and $87 \%$ respectively. Table 6 (Box's M Result) Box's M statistics was 1.964 with $P$ value 0.000 , shows the sample classification coefficients that compose the discriminant function equation i.e. $\mathrm{D}=-0.122$ (ba-ans $)+0.186(\mathrm{n}$-ans $+0.410(\mathrm{ma}-\mathrm{wd})$. Figure 4 (Histograms of discriminant scores: Male and Figure 5: Female) Histograms of discriminant scores showed that male and female have separate distribution of the data. Classification results in Table 7 (classification results) showed, 91.3\% males correctly classified in the data, on the basis of discriminant function we made, similarly, $97.1 \%$ females were correctly classified in their specific group by the help of this discriminant function. The percentage of 
skulls correctly classified with this function was $94.2 \%$.

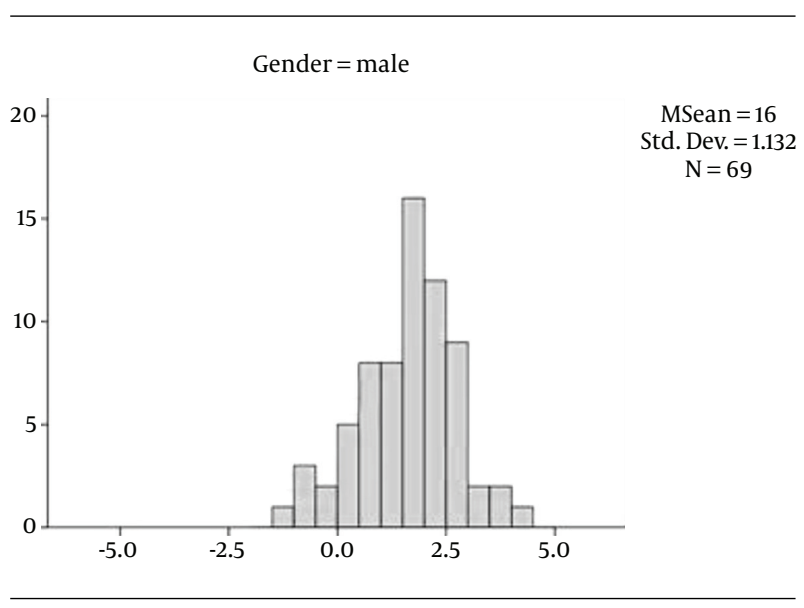

Figure 4. Histograms of Discriminant Scores: Male

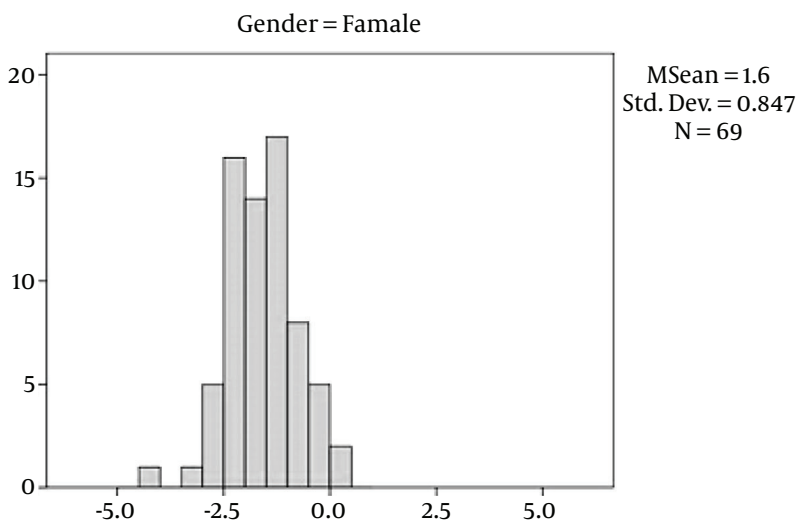

Figure 5. Histograms of Discriminant Scores: Female

\section{Discussion}

It is common knowledge that men regardless of their ethnicity have a larger stature than women, more robust cranial and facial features, along with greater muscularity, strength, and speed (4). Male tooth size exceeds that of female, pre and Post natal hormonal levels differ, growth rates vary, and diseases affect the sex differentially (5).

Rogers (6) reported although the craniofacial growth pattern among the two sexes is essentially the same, sexual dimorphism observed is the result of early attainment of skeletal maturity in women as compared to men. Further, there is variation in the growth of the different parts of the skull, with sexual differences being best defined in late growing structures of the skull, such as lower facial region, facial depth and mastoid process. On the other hand, cranial base and upper face are middle growing regions in which some sexual differences can be evident, but are not likely to be the most distinctive.

In total anterior face height and upper anterior face height, sex differences were highly significant but extreme typological differences appear to override the growth characteristics that are usually attributed to sexual dimor$\operatorname{phism}(7)$.

The mastoid region used in this study, being a part of temporal bone, is recognized as being the most protected and resistant to damage, due to its anatomical position at the base of skull, these findings have been reconfirmed by many authors Kloiber, Weels, Gejval, Spence as cited by Wall and Henke (8).

Results of the present study are consistent with these findings as all the linear measurements were greater in males as compared to females.

Results indicate that, Important size-related variables that were captured by the discriminant analysis were anterior face height, upper face height, frontal sinus height, mastoidale to SN plane, mastoidale to Frankhfort plane, and cranial base length. The derived discriminant functional equation in the present study was $82.0 \%$ accurate in differentiating the men and women. Franklin et al. (9) , reported an accuracy of 77 to $80 \%$ in sexual discrimination using 8 cephalometric variables. Naikmasur et al. (3), claimed accuracy of $81.5 \%$ and $88.2 \%$ respectively by comparing the reliability of craniomandibular parameters in South Indian and Indian immigrants of Tibetan population using 11 variables on lateral and frontal cephalograms. Hasio et al. (1), studied 100 lateral cephalograms of Taiwanese origin and claimed $100 \%$ accuracy in sex determination using 18 cephalometric parameters.

Results on a French sample, where 95.6\% accuracy and was achieved by Veyre-Goulet et al. (10). Bigoni et al. (11), also claimed 99\% - 100\% correct sex classification on a known sex Central European sample using 3 dimensional coordinates.

The variations in the result in different population may be due to the inconsistency in the position of landmarks of the skull in different populations (12). Craniofacial growth like mastoid region, zygomatic process and the ridges of occipital bone are influenced by nutrition, environment and genetic factors (13).

Lateral radiographs are generally available to forensic anthropologists and, as shown in this and other studies, introduce greater gender discriminating accuracy into forensic practice without the need for expensive equipment or computer programs. 
Table 3. Group Statistics According to Sex and in Total

\begin{tabular}{|c|c|c|c|c|}
\hline Parameters & Male & Female & Total & PValue \\
\hline sco & $16.1957 \pm 3.82447$ & $15.7971 \pm 3.39368$ & $15.9964 \pm 3.60783$ & 0.518 \\
\hline GSgN & $4.1159 \pm 1.29236$ & $2.0870 \pm 0.88682$ & $3.1014 \pm 1.50202$ & 0.000 \\
\hline SgGM & $1.1667 \pm 0.65679$ & $0.5580 \pm 0.51117$ & $0.8623 \pm 0.66114$ & 0.000 \\
\hline BaANS & $99.8986 \pm 6.95605$ & $94.5942 \pm 5.61070$ & $97.2464 \pm 6.83573$ & 0.000 \\
\hline BaN & $10.954 \pm 8.28283$ & $10.130 \pm 5.39145$ & $10.542 \pm 8.09597$ & 0.000 \\
\hline NANS & $63.1739 \pm 79.25683$ & $49.8406 \pm 3.93186$ & $56.5072 \pm 56.30577$ & 0.165 \\
\hline NMe & $12.203 \pm 10.86409$ & $11.065 \pm 7.50260$ & $11.634 \pm 10.91406$ & 0.000 \\
\hline FsWd & $11.5507 \pm 2.98174$ & $9.2319 \pm 2.03748$ & $10.3913 \pm 2.79777$ & 0.000 \\
\hline FsHt & $29.6159 \pm 6.12861$ & $26.5797 \pm 7.09268$ & $28.0978 \pm 6.77745$ & 0.008 \\
\hline MaSN & $46.8406 \pm 5.48426$ & $41.3768 \pm 5.40996$ & $44.1087 \pm 6.08058$ & 0.000 \\
\hline MaFH & $31.6594 \pm 3.81993$ & $28.0725 \pm 3.76641$ & $29.8659 \pm 4.18615$ & 0.000 \\
\hline MaWd & $20.3478 \pm 3.00405$ & $18.5362 \pm 3.64441$ & $19.4420 \pm 3.44936$ & 0.002 \\
\hline MaHt & $10.1304 \pm 2.26815$ & $8.7536 \pm 2.43990$ & $9.4420 \pm 2.44656$ & 0.001 \\
\hline ANSMe & $70.4928 \pm 7.16327$ & $61.7971 \pm 5.60352$ & $66.1449 \pm 7.75214$ & 0.000 \\
\hline SL & $7.6304 \pm 1.62619$ & $7.1304 \pm 1.58033$ & $7.3804 \pm 1.61715$ & 0.069 \\
\hline sw & $11.3913 \pm 1.47745$ & $11.0870 \pm 1.41150$ & $11.2391 \pm 1.44765$ & 0.218 \\
\hline SHtPost & $8.5870 \pm 1.55051$ & $8.4348 \pm 1.57628$ & $8.5109 \pm 1.55960$ & 0.568 \\
\hline SHtAnt & $8.9710 \pm 1.58319$ & $8.4783 \pm 1.58679$ & $8.7246 \pm 1.59844$ & 0.070 \\
\hline GSIPI & $1.0146 \pm 0.36644$ & $0.8407 \pm 0.28523$ & $0.9277 \pm 0.33860$ & 0.002 \\
\hline GPI & $6.8353 \pm 2.34182$ & $3.3757 \pm 1.56451$ & $5.1055 \pm 2.63648$ & 0.000 \\
\hline ULTC & $1.0150 \pm 0.25998$ & $1.1611 \pm 0.30618$ & $1.0880 \pm 0.29232$ & 0.003 \\
\hline GMSN & $98.2754 \pm 6.48728$ & $89.2754 \pm 12.00721$ & $93.7754 \pm 10.62295$ & 0.000 \\
\hline GMFH & $104.84 \pm 5.82748$ & $98.6957 \pm 5.94411$ & $101.77 \pm 6.62586$ & 0.000 \\
\hline GMBaN & $77.5942 \pm 5.81913$ & $70.5797 \pm 6.12230$ & $74.0870 \pm 6.91394$ & 0.000 \\
\hline MSgG & $170.33 \pm 6.11331$ & $174.04 \pm 2.89744$ & $172.19 \pm 5.11695$ & 0.000 \\
\hline BaNMe & $56.1159 \pm 3.82921$ & $64.2319 \pm 6.030661$ & $60.1739 \pm 4.276722$ & 0.267 \\
\hline NMEANS & $9.4348 \pm 3.96855$ & $10.2464 \pm 3.19653$ & $9.8406 \pm 3.61313$ & 0.188 \\
\hline SNMe & $76.7391 \pm 4.41139$ & $77.0870 \pm 4.55599$ & $76.9130 \pm 4.47128$ & 0.649 \\
\hline SNAr & $123.61 \pm 5.67299$ & $124.39 \pm 6.39673$ & $124.00 \pm 6.03639$ & 0.448 \\
\hline GNGSg & $29.3913 \pm 7.92097$ & $19.3043 \pm 6.90759$ & $24.3478 \pm 8.96925$ & 0.000 \\
\hline GSGM & $86.8406 \pm 5.76660$ & $78.8116 \pm 6.03245$ & $82.8261 \pm 7.12753$ & 0.000 \\
\hline GSSN & $11.3478 \pm 2.26109$ & $11.7681 \pm 2.40798$ & $11.5580 \pm 2.33669$ & 0.292 \\
\hline SNSMa & $129.12 \pm 5.25395$ & $130.36 \pm 5.88610$ & $129.74 \pm 5.59367$ & 0.192 \\
\hline SGN & $61.0435 \pm 5.29271$ & $63.0870 \pm 5.24051$ & $62.0652 \pm 5.34668$ & 0.024 \\
\hline
\end{tabular}

Table 4. Wilk's Lambda

\begin{tabular}{|c|c|c|c|c|}
\hline Test of 1 & Wilk's Lambda & Chi-Square & df & PValue \\
\hline 1 & 0.278 & 152.320 & 34 & 0.000 \\
\hline
\end{tabular}

Table 5. Functions at Group Centroids (Unstandardized Canonical Discriminant Functions Evaluated at Group Means)

\begin{tabular}{lc}
\hline Gender & Function 1 \\
\hline Male & 1.600 \\
Female & -1.600 \\
\hline
\end{tabular}

\subsection{Conclusions}

This is an attempt to verify the standard for sex determination based on the lateral cephalometric parameters in Pakistani population. This study was able to attain $94.2 \%$ accuracy with thirty four variable model. To obtain higher 
Table 6. Box's M Result

\begin{tabular}{|c|c|}
\hline Box's M Result & Values \\
\hline Box's M & 1.964 \\
\hline F Approx. & 2.428 \\
\hline dfi & 595 \\
\hline df2 & 5.585 \\
\hline
\end{tabular}

Table 7. Classification Results ${ }^{\mathrm{a}}$

\begin{tabular}{lcc}
\hline Gender (Original) & Group & Total \\
\cline { 2 - 3 } & Female & $2(2.9)$ \\
\hline Female & $67(97.1)$ & $69(100.0)$ \\
Male & $6(8.7)$ & $69(91.3)$ \\
\hline
\end{tabular}

${ }^{\mathrm{a}} 94.2 \%$ of original grouped cases correctly classified.

results further research of the technique with large sample size and both linear and angular cranial dimorphic traits for gender identification is proposed. The proper identification of landmarks, careful measurements and strict statistical methods will yield reliable results and will meet the needs of the forensic investigation in our country.

\section{References}

1. Hsiao TH, Chang HP, Liu KM. Sex determination by discriminant function analysis of lateral radiographic cephalometry.J Forensic Sci. 1996;41(5):792-5. [PubMed: 8789839].

2. Zeh JE, Ko D, Krogman BD, Sonntag R. A multinomial model for estimating the size of a whale population from incomplete census data. Biometrics. 1986;42(1):1-14. [PubMed: 3719047].

3. Naikmasur VG, Shrivastava R, Mutalik S. Determination of sex in South Indians and immigrant Tibetans from cephalometric analysis and discriminant functions. Forensic Sci Int. 2010;197(1-3):122.e1-6. doi: 10.1016/j.forsciint.2009.12.052

4. Beach FA. In: Human Evolution: Biosocial Perspectives. Washburn SL, McCown ER, editors. Menlo Park: Cummings; 1978. Human sexuality and evolution.
5. Gilbert RI, Mielke JH. The Analysis of Prehistoric Diets. Orlando: Academic Press; 2000. Growth rates and sexual dimorphism in evolutionary perspective.

6. Rogers TL. Determining the sex of human remains through cranial morphology. J Forensic Sci. 2005;50(3):493-500. [PubMed: 15932077].

7. Nanda SK. Patterns of vertical growth in the face. Am J Orthodont Dent Orthoped. 1988;93(2):103-16. doi: 10.1016/0889-5406(88)90287-9.

8. Keen JA. A study of the differences between male and female skulls. Am J Phys Anthropol. 1950;8(1):65-80. doi: 10.1002/ajpa.1330080113.

9. Franklin D, Freedman L, Milne N. Sexual dimorphism and discriminant function sexing in indigenous South African crania. Homo. 2005;55(3):213-28. [PubMed: 15803767].

10. Veyre-Goulet SA, Mercier C, Robin O, Guerin C. Recent human sexual dimorphism study using cephalometric plots on lateral teleradiography and discriminant function analysis. JForensic Sci. 2008;53(4):7869.

11. Bigoni L, Veleminska J, Bruzek J. Three-dimensional geometric morphometric analysis of cranio-facial sexual dimorphism in a Central European sample of known sex. Homo. 2010;61(1):16-32. doi: 10.1016/j.jchb.2009.09.004. [PubMed: 20152969].

12. Glucksmann A. Sexual dimorphism in human and mammalian biology and pathology. Academic Press; 1981.

13. Galdames IC, Matamala DAZ, Smith RL. Evaluating accuracy and precision in morphologic traits for sexual dimorphism in malnutrition human skull: a comparative study. Int J Morphol. 2008;26(4):876-83. 